\title{
Evaluation of the Effect of Lime Content on the California Bearing Ratio of Silty Soils: Case of Fombap District
}

\section{Willy Chance Guimezap Kenou1,2,3* François Ngapgue ${ }^{1,2,4}$, Jules Hermann Keyangue Tchouata ${ }^{5}$, Vladimir Willianov Keubou Tatapzia ${ }^{4}$, Walter Jovic Kenou Jogo ${ }^{6}$}

\author{
${ }^{1}$ Research Unit of Mechanics and Physical Systems Modeling (UR2MPS), Faculty of Sciences, University of Dschang, Dschang, \\ Cameroon \\ ${ }^{2}$ Laboratory of Engineering, Industrial Systems and Environment (LISIE), FOTSO Victor University Institute of Technology, \\ University of Dschang, Dschang, Cameroon \\ ${ }^{3}$ Research Center for Innovation and Entrepreneurship (PRIE), Institut Universitaire de la Cote, Douala, Cameroon \\ ${ }^{4}$ Laboratory of Environmental Geology, Faculty of Sciences, University of Dschang, Dschang, Cameroon \\ ${ }^{5}$ School of Geology and Mining Engineering (SGME), University of Ngaoundéré, Ngaoundéré, Cameroon \\ ${ }^{6}$ Faculty of Arts, Humanities and Social Sciences (FALSH), University of Yaoundé 1, Yaoundé, Cameroon \\ Email: *willy.kenou@myiuc.com, willychance@gmail.com
}

How to cite this paper: Guimezap Kenou, W.C., Ngapgue, F., Keyangue Tchouata, J.H., Keubou Tatapzia, V.W. and Kenou Jogo, W.J. (2020) Evaluation of the Effect of Lime Content on the California Bearing Ratio of Silty Soils: Case of Fombap District. Open Journal of Geology, 10, 1059-1071. https://doi.org/10.4236/ojg.2020.1011051

Received: October 25, 2020

Accepted: November 22, 2020

Published: November 25, 2020

Copyright $\odot 2020$ by author(s) and Scientific Research Publishing Inc. This work is licensed under the Creative Commons Attribution International License (CC BY 4.0).

http://creativecommons.org/licenses/by/4.0/

\section{(c) (i) Open Access}

\begin{abstract}
The present study is inscribed within the framework of the amelioration of the soils of the Santchou plain for employment as pavement subgrade. The bearing capacity proposed by these soils at their respective optimum dry densities is relatively small, although most of these experimental California Bearing Ratio (CBR) values of the studied soils are more important than the ones prescribed by the American Association of State Highway and Transportation Officials Classification system (AASHTO) for A5, A6, and A7 types. The stabilization of this soils with lime has been chosen to improve the bearing capacity and by association, their resilient modulus. The results of this study show that the increase of lime content is not proportional with the increase of the expected mechanical performances. In fact, the literature explains that when the lime content arrives at an optimum, the mechanical parameters no longer increase, but decrease significantly. After this optimum, the soil stabilization no longer shows advantages in the increase of geo-mechanical properties of soils.
\end{abstract}

\section{Keywords}

Soil Classification, Lime Content, California Bearing Ratio, Soil Stabilization, Subgrade 


\section{Introduction}

The Melong-Fongo Tongo Roadway pavement failure is a very serious problem that causes unnecessary delay in traffic flow, distorts pavement aesthetics and breakdown of vehicle. These failures can be due to factors such as properties of construction materials, subgrade conditions, environmental conditions, and traffic loading. The types of distresses observed, associated to the relief of the region indicates clearly that the origin of the majority of road pathologies in the studied axle, is associated with subgrade ground defects [1] [2].

The soils in this area being mainly fine grained soils by granularity, in particular silty sand to sandy silts, are supposed to offer poor bearing capacity according to the literature [3]. The road studied crosses the Santchou plain which, being the bed of three river watersheds, becomes a marshy area during the four months' rainy season. The soil nature associated to the local hydrography suggests lime stabilization as one of the adequate solutions, which will improve the lifespan of the pavement. In fact, the addition of lime to the soil should increase its geo-mechanical performances, and decrease its sensibility to water, in particular, to the infiltrations due to the rise of the water table. Increasing strength and load-bearing capacity, as well as improving durability, are the main objectives of soil stabilization [4] [5] [6] [7]. Although, the pavement subgrade can be made up of a wide variety of soil types, which shows different response to ameliorations, engineers should be able to find the appropriate process to make the stabilization of this section subgrade a reliable solution for the lifespan of the pavement.

In this work, some soils along the axle Melong-Fongo Tongo, especially at the Fombap district, were studied in order to know how their performance as pavement subgrade would evolve with lime stabilization.

\section{Literature}

\subsection{Requirements for Roadway Subgrades}

Although pavements fail from the top, pavement systems generally start to deteriorate from the bottom (subgrade), the characteristic of the subgrade, their capacity to resist to traffic and environmental assaults often determines the service life of a road [2]. Subgrade performance generally depends on two interrelated characteristics: The Load-bearing capacity which is the ability to support loads is transmitted from the pavement structure, and Volume changes of the subgrade, when this one is exposed to excessive moisture [8]. The most critical element for subgrade construction is to develop a CBR of at least 10 in the prepared subgrade using on-site, borrow, or modified soil [8]. According to the Design Guide for Improved Quality of Roadway Subgrades and Subbases, the general rating of soil for use as pavement subgrade are in Table 1.

\subsection{Effects of Lime Stabilization}

Lime stabilization can be effective only with materials which contain enough 
Table 1. Rating of CBR values for subgrade soils.

\begin{tabular}{ccc}
\hline California Bearing Ratio & Rating \\
\hline 20 to 30 & Very Good \\
10 to 20 & Fair-Good \\
5 to 10 & Poor-Fair \\
$<5$ & Very poor \\
\hline
\end{tabular}

Source: design guide for improved quality of roadway Subgrades and Subbases [8].

clay for a positive reaction to take place and that attempt to use Lime as a binding material will not be successful [9]. Lime is suitable for treating lateritic soil with high clay and silt contents [7].

The addition of lime contributes towards the improvement of soil workability but not automatically to an increase in strength. Lime added in excess of the fixation point is utilized in the cementation process and the effectiveness of lime stabilization is dependent upon the development of reaction products formed from the attack of lime on the minerals in a deposit of clay. The amount of strength increase in a soil that can be produced by adding lime is dependent on the pozzolans present. When the desirable pozzolans are available, they react readily with lime to improve the strength of soil-lime mixtures. Nonetheless it would appear that the absolute amount of silica or alumina required to sustain pozzolanic reaction in soils is relatively small [10]. When lime is added to clay soils, calcium ions are combined initially with or adsorbed by clay minerals. These changes continue up to the lime fixation point [11]. Furthermore, a montmorillonite soil mixed with a low lime content attained maximum strength in less time than one to which a higher content of lime had been added. Indeed, strength does not increase linearly with lime content, and excessive addition of lime reduces strength. This is due to the fact that lime itself has neither appreciable friction nor cohesion [10].

The Decreases of the compressive strength of stabilized soils can be quite significant and at times they may exceed 30\%. They are associated with considerable decreases in dry density. Hence it is important to determine the optimum lime content for mix design [12]. Optimum lime content represents the point of lime saturation and may move, according to clay mineral content, towards higher increments with increasing length of curing time. For instance, this optimum and its associated strength generally [10].

Soil agglomerate size obviously has an influence on stabilization from treatment with lime in the field [4]. If there is a pattern of hardening of the untreated soils, lime treated soils both hardens and softens, this pattern is related to the agglomerate particle size. In general, softening gradually translates into hardening with an increase in the soil agglomerate size from $0.5 \mathrm{~mm}$ to $6 \mathrm{~cm}$. In fact, the CBR values of lime treated soil are higher than those of untreated soil for soil agglomerate size that ranges between $0.5 \mathrm{~mm}$ to two $\mathrm{cm}$. beyond this range; the addition of lime to improve bearing capacity is ineffective. Hence, controlling of 
soil agglomerate size is an important construction procedure in the field therefore [4].

\section{Material and Methodology}

\subsection{Materials}

The road section between Melong and Fongo-Tongo, being 29 kilometers, in order to have representative samples of the area crossing by the road section, 16 sites were chosen in different parts of the road section. However; points 1 to 8 allow us, with a spacing varying between 2.5 and 5 kilometers, to cover the entire section as control samples, an in-depth study was carried out in the Locality of Fombap where 8 sites were selected between the sites 1 and 2. In the same way, the 8 sites covering the Locality of Fombap are the sites 9 to 16, with an average distance of 500 meters between the different samples along the provincial road in the said locality. In the road section crossing the FOMBAP district, the effect of lime stabilization on soils mechanical parameters has been analysed. Figure 1 shows the samples distribution along road section and the GPS coordinates of the chosen sites. These sites are far apart from 15 meters to 200 meters from the road section to avoid the embankments associated to the road section pavement. In each site, the sampling was carried out in wells deeper than $100 \mathrm{~cm}$ in order to avoid the first layer of organic soil.

The samples have been submitted to laboratory testing in order to get their properties before being submitted to four soil classification systems. Regarding their respective Grain Size Analysis, the studied soils are mainly silty. In fact, the United States Department of Agriculture (USDA) textural classification system classified them among the Loamy Soils, the Unified Soil Classification System (USCS) recognize them as Sandy Silts to Silty Sand with Gravel. According the AASHTO, the soils studied are classified, as Silty to Clayed materials, the different groups in which they belong are the groups A-5 for P1, P14, P15 and the group A-7 for the remaining soils (Table 2).

The silty sand (SM) soils show slight to medium compressivity and expansion ability with fair subgrade strength, and the sandy elastic silt (MH) soils show poor subgrade strength associated with high abilities to compressibility and expansion. ASTM D3282-09 Standard Practice rates these different groups to be fair to poor for a use as road subgrade for Classification of Soils and Soil-Aggregate Mixtures for Highway Construction Purposes. Washington State Department of Transportation has also estimated the range of the values of the California bearing ratio and the elastic modulus of the soils based on their USCS classification (Table 3).

Lime sample used in this study was purchased from local market. $\mathrm{CaO}$, $\mathrm{CaO}^{*} \mathrm{MgO}, \mathrm{Ca}(\mathrm{OH})_{2}, \mathrm{Ca}(\mathrm{OH})_{2},{ }^{\star} \mathrm{MgO}, \mathrm{Ca}(\mathrm{OH})_{2},{ }^{*} \mathrm{Mg}(\mathrm{OH})_{2}$ are the basic constituents of the lime. It has got proper mineralogy to produce long term strength, reduction quality in shrinking, swelling and soil plasticity with adequate durability. 

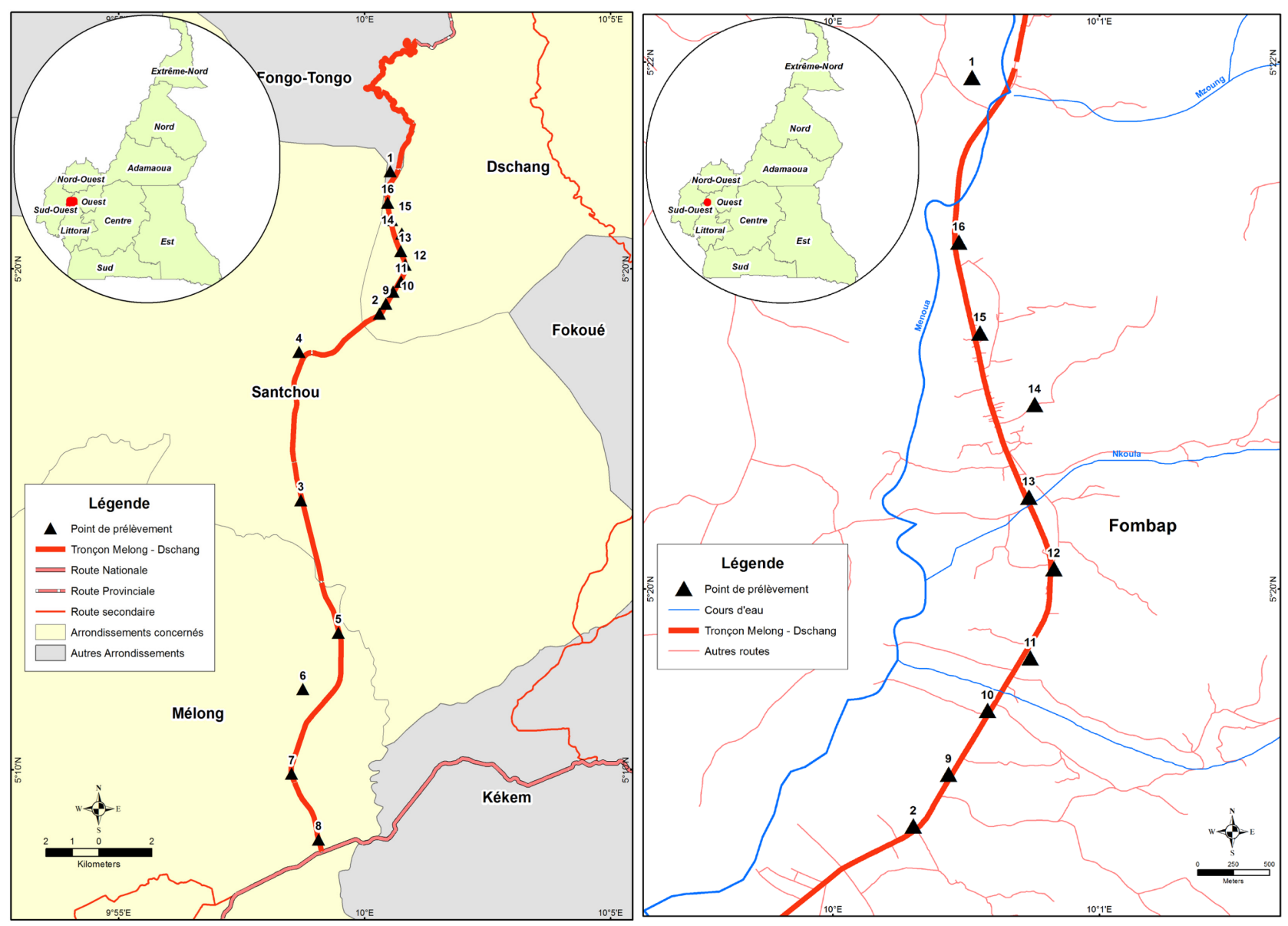

Figure 1. Sample collection points on administrative map of the Fombap District (Sources: Data: Data collected in the field on the 27/03/2020; Basemap: Adapted from the administrative map of Cameroon, INC, 2016).

Table 2. Soil Classification of samples studied.

\begin{tabular}{ccccc}
\hline & \multicolumn{2}{c}{ Multipurpose Classification Systems } & \multicolumn{2}{c}{ Highway Engineering oriented Classification Systems } \\
\hline Soil Sample & USDA Soil Textural & USCS & AASHTO & French Road Earthworks Manual (GTR) \\
\hline P 1 & Silty Loam & Sandy Elastic Silt (MH) & A-5 & A2 h \\
P 2 & Silty Loam & Silty Sand With Gravel (SM) & A-7-5 & A2 m \\
P 9 & Silty Loam & Silty Sand (SM) & A-7-6 & A2 h \\
P 10 & Sandy Loam & Silty Sand (SM) & A-7-5 & A2 th \\
P 11 & Sandy Loam & Sandy Elastic Silt (MH) & A-7-5 & A2 h \\
P 12 & Silty Loam & Sandy Elastic Silt (MH) & A-5 & A1 m \\
P 13 & Sandy Loam & Sandy Elastic Silt (MH) & A-7-6 & A3 m \\
P 14 & Sandy Loam & Silty Sand (SM) & A-5 & A2 s \\
P 15 & Sandy Loam & Silty Sand (SM) & A-5 & A3 s \\
P 16 & Silty Loam & Silty Sand With Gravel (SM) & A-7-6 & \\
\hline
\end{tabular}

Table 3. Expected values of bearing capacity and elastic modulus.

\begin{tabular}{ccc}
\hline Soil Type & CBR Value & Elastic Modulus (MPa) \\
\hline Silty Soils (ML, MH) & 3 to 15 & 34 to 138 \\
Sandy Soils (SW, SP, SM, SC) & 4 to 30 & 48 to 207 \\
\hline
\end{tabular}

Source: Washington state department of transportation and pavement guide. 


\subsection{Methodology and Laboratory Testing}

The objectives of these tests will be to evaluate the evolution of soil performance as pavement subgrade by the lime content. The California bearing Ratio (CBR) test, allows the mechanical characterization of natural and stabilized soils compacted to their optimum, for a use as embankments, or road subgrade. This test is used for pavement structures design and the orientation of earthworks. The California bearing ratio is the ratio of force per unit area required by a circular plunger of $50 \mathrm{~mm}$ diameter at the rate of $1.25 \mathrm{~mm}$ per minute, to penetrate into a soil mass conditioned according to the standards NF P 94-078 at its optimum moisture content. In this study, the compacted specimens were soaked in water for 96 hours before subjected to the punching in the CBR testing machine.

\section{Results and Discussions}

The effects of stabilization on the geo-mechanical properties can be difficult to predict because of the lack of uniformity in the nature of soils, particularly in their chemical composition and granular distribution. The next paragraphs will show the results obtained after the CBR tests for natural and stabilized soils. Thus, comparisons at different lime contents will be carried out in order to judge the optimal stabilization percentages for the improvement of the bearing capacity of FOMBAP soils, for stress-strain curves of some soils compacted at 55 strokes, and for the CBR index values obtained.

\section{Some Stress-Strain Curves}

Overall, the stress-deformation curves of the soils evolve according to their lime content, however this evolution is not identical with regards to the variations presented by the studied samples. In Figures 2-6, are listed the stress-deformation curves of soils $2,10,12,15$ and 16 compacted at 55 strokes, with different lime contents.

Sample 2

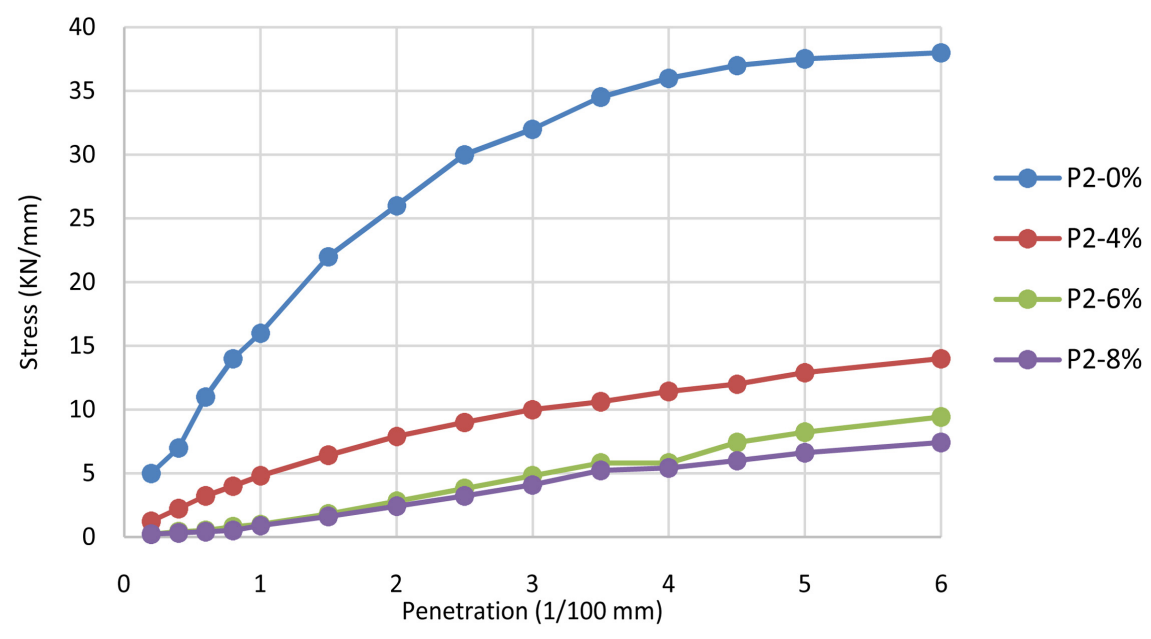

Figure 2. Stress - Strain curves for sample 2 (at lime content: 0, 4\%, 6\%, and 8\%). 


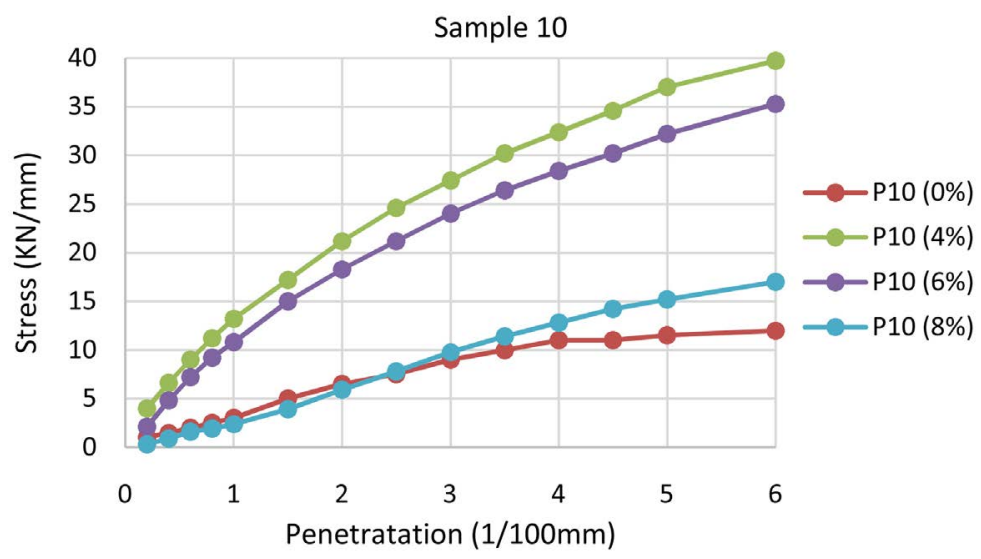

Figure 3. Stress - Strain curves for sample 10 (at lime content: $0,4 \%, 6 \%$, and $8 \%)$.

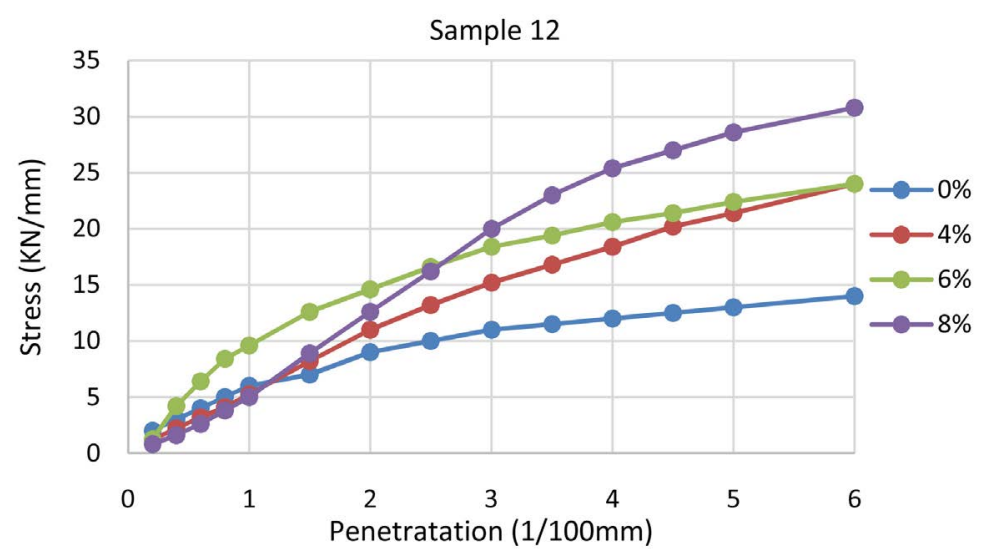

Figure 4. Stress - Strain curves for sample 12 (at lime content: 0, 4\%, 6\%, and $8 \%)$.

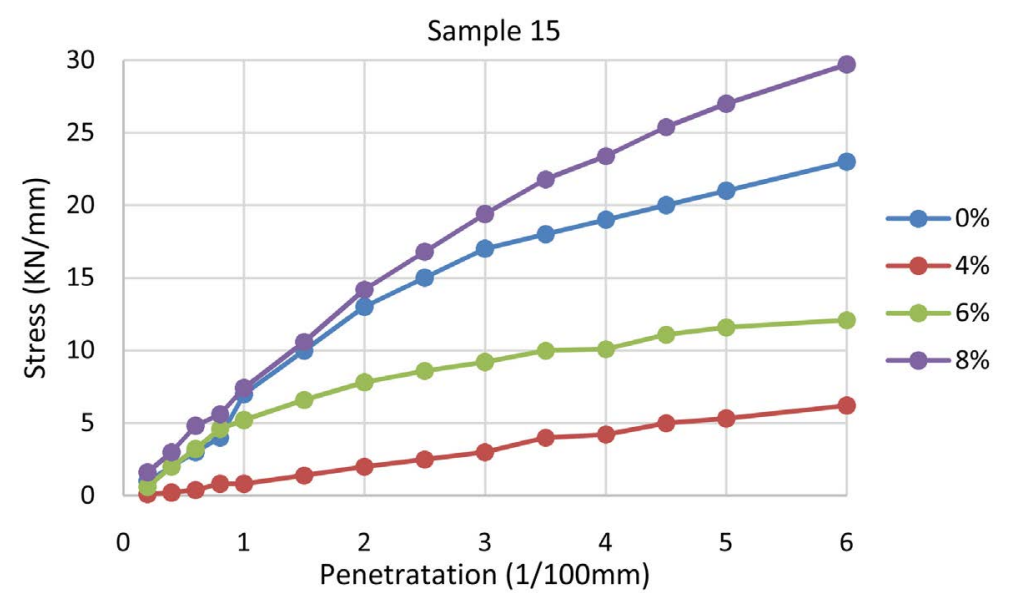

Figure 5. Stress - Strain curves for sample 15 (at lime content: 0, 4\%, 6\%, and $8 \%)$.

In relation to Figure 2, lime stabilization considerably decreases the bearing strength as well as the elastic modulus, which is assimilated to the slope of the stress-strain curve. The stabilization of the sample 2 at $4 \%, 6 \%$ and $8 \%$ is not 


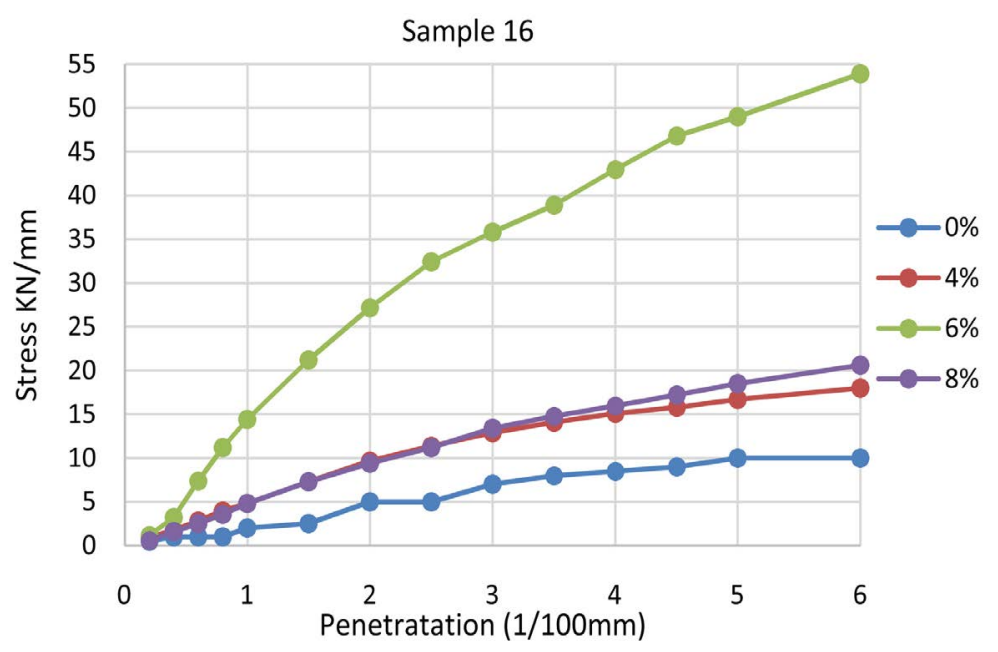

Figure 6. Stress - Strain curves for sample 16 (at lime content: $0,4 \%, 6 \%$, and $8 \%)$.

beneficial for the improvement of its mechanical performances for a use on flat ground, since it leads to an increasing fall of the bearing parameters beyond $4 \%$ of stabilization.

On the other hand, the stabilization of sample 10 (Figure 3 ) is beneficial between 0 and $4 \%$ of lime with a growth of the bearing capacity of approximately $300 \%$, going from 15 to $40 \mathrm{KN} / \mathrm{mm}$. but at higher lime contents, the obtained performances decrease. Thus, between $4 \%$ and $6 \%$, the bearing capacity decreases by $10 \%$. In addition, between $6 \%$ and $8 \%$, it decreases by $70 \%$, its value approaching that proposed by the natural soil. We can conclude that at more than $6 \%$ of lime, the stabilization becomes inefficient. The sample 12 (Figure 4) show increase of the CBR with the percentage of lime, although that the CBR curves at $4 \%$ and $6 \%$ which are getting closer with the increase of the penetration, reaches $24 \mathrm{KN} / \mathrm{mm}$, representing an increase of $67 \%$ of the value of the natural sample. The increase of lime content between $4 \%$ and $6 \%$ is not efficient, but at $8 \%$ of lime content, the CBR curve increases significantly to cross the value of 30 $\mathrm{KN} / \mathrm{mm}$, with is twice (100\%) the value obtained for the natural soil.

The stress-strain curves in Figure 5 show a different reaction of Sample 15 to lime stabilization. While the natural soil reaches $23 \mathrm{KN} / \mathrm{mm}$, the additions of lime at $4 \%$ cause a drop in strength, the stress-strain curve now reaches 6.5 $\mathrm{KN} / \mathrm{mm}$, i.e. a decrease of $70 \%$. While at $6 \%$ and $8 \%$ of lime content, sol 15 shows an increase in strength, which doubles between $4 \%$ and $6 \%$ of lime and reaches $12.5 \mathrm{KN} / \mathrm{mm}$. Then between $6 \%$ and $8 \%$, the increase in strength is $140 \%$, the stress-strain curve at $8 \%$ then reaches $30 \mathrm{KN} / \mathrm{mm}$, i.e. $33 \%$ more than the natural sample. In the third case, the optimal performances are proposed by a $6 \%$ stabilization. thus, the resistance of the sample 16 (Figure 3) found is maximal at $6 \%$ lime content with $55 \mathrm{KN} / \mathrm{mm}$ at $6 \mathrm{~mm}$ of penetration, that is to say approximately 3 times more than the performances shown by the stabilization at $4 \%$ and $8 \%$, and 5 times more than the natural soil. 


\section{California Bearing Ratio}

In Table 4, you will find the CBR values of the 10 sites studied, in their natural state, and stabilized with $4 \%, 6 \%$ and $8 \%$ lime. The average CBR values for natural soils is 12.7 while those for $4 \%, 6 \%$, and $8 \%$ lime soils are $27.2,27.5$, and 29.9, respectively. We therefore observed that the overall performance of soils is doubled with $4 \%$ stabilization. Thus, as a road subgrade, the proposed performances of the studied soils, which were acceptable before stabilization, becomes very good with an addition of $4 \%$ lime. However, the weak evolution of the average CBR values with $6 \%$ and $8 \%$ lime shows that it would be beneficial, notably from an economic point of view, if the engineers did not exceed a contribution of $4 \%$ lime in earthworks. We then conclude that the addition is beneficial in a global way for the improvement of the CBR value.

However, the gain carried out compared to the performances of the natural soil can question in some cases the objectivity of the choice of this solution. Moreover, the process of stabilization of a roadbed involves considerable additional costs in the earthworks. In view of its results, it is difficult to quantify the evolution of the CBR value by the lime content, as the bearing capacity of each material evolves in a different way at stabilization. However, three modes of behavior have been identified and are described in Figures 7-9.

In Figure 7, the samples show their optimum lime content respectively at $4 \%$ for soils 1,9 , and 13 , but their CBR values failed significantly at $6 \%$ to increase at $8 \%$, when the soil 16 has its optimum lime content at $6 \%$. In Figure 8, the CBR value of the Sample 2 decreases continuously from 25 to 8, with the increase of the lime content. While the soil stabilization is not benefit for the bearing performances of the soil 2, for the soils 11 and 12, the CBR values increase with the addition of lime until the double or the triple.

In Figure 9, the sample 15 shows a CBR value which decreases at $4 \%$ of lime to 7 but increases continuously to 13 at $6 \%$ of lime. At $8 \%$ of lime, the increase of

Table 4. California Bearing Ration of the natural and treated samples.

\begin{tabular}{ccccc}
\hline $\begin{array}{c}\text { Soil } \\
\text { Samples }\end{array}$ & $\begin{array}{c}\text { Soaked CBR } \\
\text { 0\% Lime }\end{array}$ & $\begin{array}{c}\text { Soaked CBR }+ \\
\text { 4\% Lime }\end{array}$ & $\begin{array}{c}\text { Soaked CBR }+ \\
\text { 6\% Lime }\end{array}$ & $\begin{array}{c}\text { Soaked CBR + } \\
\text { 8\% Lime }\end{array}$ \\
\hline P 1 & 3 & 14 & 7 & 37 \\
P 2 & 24 & 17 & 10 & 8 \\
P 9 & 12 & 33 & 27 & 60 \\
P 10 & 11 & 48 & 42 & 20 \\
P 11 & 8 & 11 & 16 & 19 \\
P 12 & 9 & 28 & 29 & 37 \\
P 13 & 14 & 54 & 29 & 41 \\
P 14 & 13 & 38 & 34 & 18 \\
P 15 & 18 & 7 & 13 & 35 \\
P 16 & 16 & 22 & 68 & 24 \\
Average & 12.625 & 27.2 & 27.5 & 29.9 \\
\hline
\end{tabular}




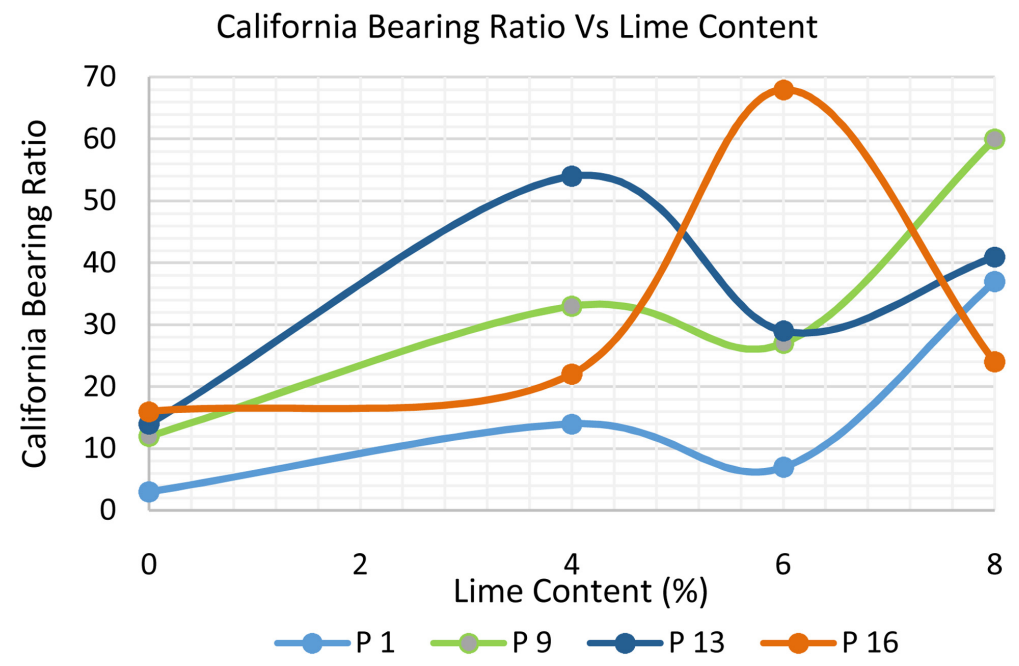

Figure 7. California bearing ratio versus lime content (site 1, 9, 13, and 16).

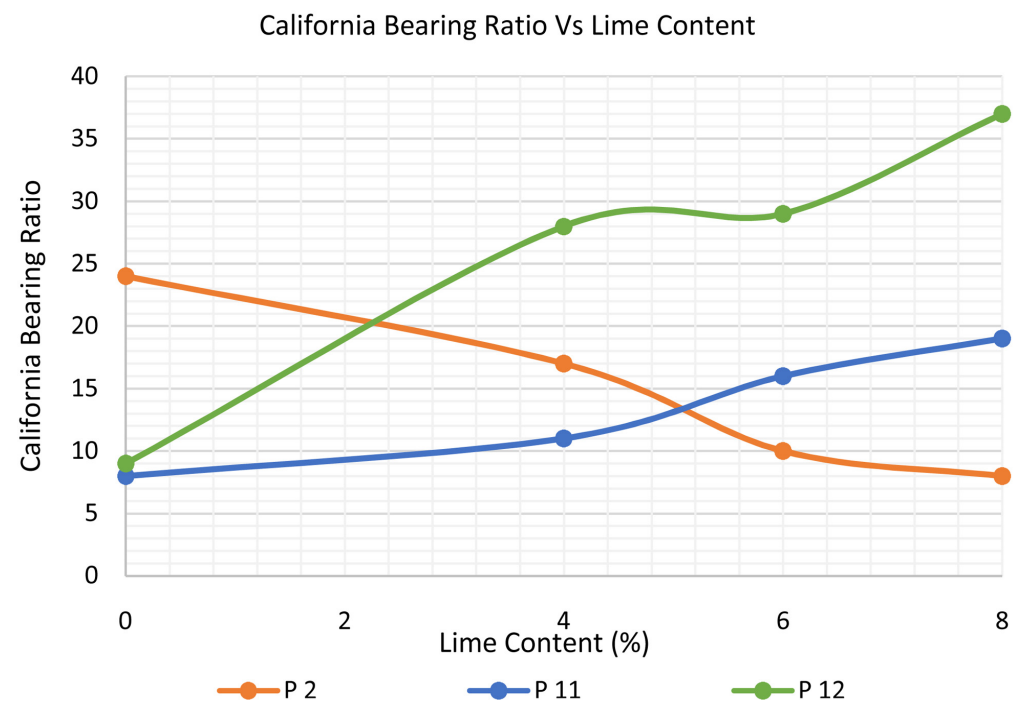

Figure 8. California bearing ratio versus lime content (site 2, 11, and 12).

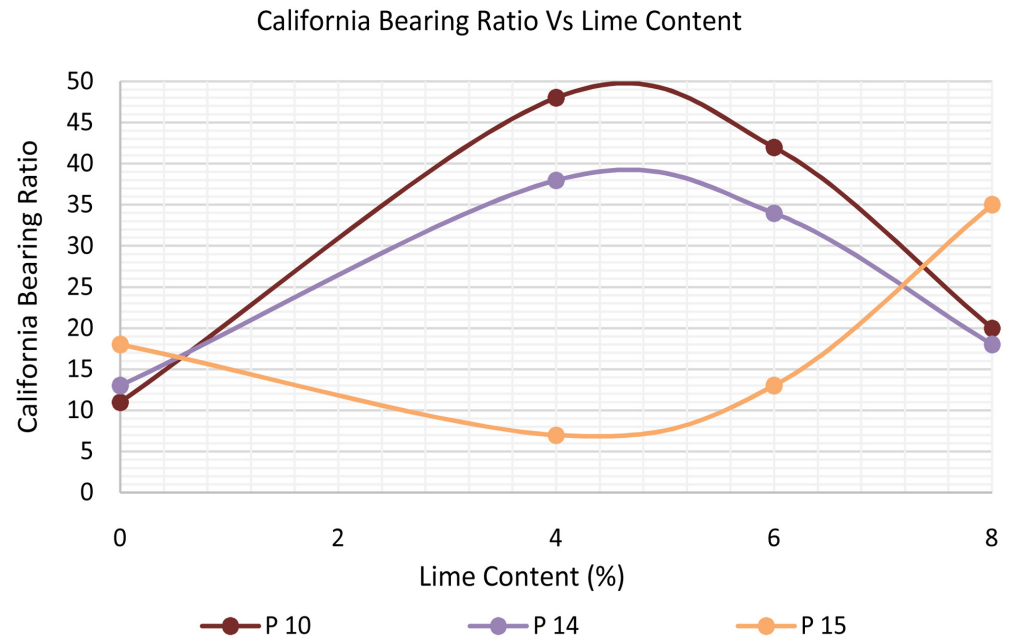

Figure 9. California bearing ratio versus lime content (site 10, 14, and 15). 
the $\mathrm{CBR}$ reaches 36 , which represents around $75 \%$ of increase of the natural soil, is CBR value. The evolution of CBR for samples 10 and 14 have this behavior because the bearing capacity is multiplied by 4 and 5 at $4 \%$ of lime content, and decreases to return gradually near 20 of CBR value which represents the double of CBR value of the natural soil.

In conclusion, we noticed 3 types of behavior of the studied soils at lime stabilization. Samples 16, 10 and 14 clearly show that the optimal lime content is respectively $6 \%$ and $4 \%$. Soils 2,11 and 12 have a linear reaction to the different levels of lime stabilization. Thus, soil 2 has a decreasing bearing capacity while the other soils (11 and 12) have a gradual increase in bearing capacity with the addition of lime. And finally, soils 15, 1, 9 and 13, which have incoherent evolution of their bearing capacity. Thus, between $0,4 \%$ and $6 \%$ of lime content, the bearing capacity goes through phases of growth, then of decrease and finally of growth or vice versa. These evolutions can be explained by the influence of the setting reaction with the clay particles, which leads to a growth of the bearing capacity up to the threshold lime content [10] [13], and then a decrease after this one combined with that of the granular size distribution, which influences the efficiency of lime stabilization [4]. However, after the optimum lime content is exceeded, this granular size distribution is modified by the lime that did not participate in the setting reaction. Thus, after the optimum lime content has been reached, the remaining lime becomes a granulate, which adjusts the grain size of the natural material, thus leading to the modification of the consistency parameters, and then to an increase in compacity and thus in general bearing capacity.

\section{Conclusion}

The process of stabilizing subgrades in highway construction must be studied before being implemented. Indeed, the determination of average values of the optimal lime contents associated with the studied soils, the efficiency of the stabilization on the mechanical performances at the said content, and bearing capacitydrop if this one is exceeded, are the parameters that must be determined in laboratory. The impact of this stabilization can also affected by the variations in the grain size distribution of the soils encountered along the studied road axis. Thus, in our study, after analysis of the tests carried out on the 10 samples of the 7 Kilometers of highway crossing the FOMBAP district, the addition of $4 \%$ lime provided an overall growth of the CBR of $115 \%$, but the addition of $2 \%$ more lime does not result in any significant improvement of the overall bearing capacity. With regard to the stress-strain curves, stabilization at $4 \%$ lime results in a stiffening of the subgrade soil, thus increasing its modulus of elasticity. The improvement of this parameter will allow the pavement to withstand higher traffic loads, and consequently to limit in the short terms lumping, and in the long term, the rutting phenomena. In Cameroon, since lime is a hydraulic binder that is 3 times more expensive by weight than Portland cement, it would be more 
economically viable to consider stabilizing the soil along a section by adopting an addition of lime at the level of the lowest optimal lime content, as this could be in excess for certain areas and consequently have a negative effect on the bearing capacity parameters.

\section{Acknowledgements}

The authors would like to thank Institut Universitaire de la Côte (IUC, Douala-Cameroon) and its Research Center for Innovation and Entrepreneurship teams for their assistance in the studies that led to the completion of this work.

\section{Conflicts of Interest}

The authors declare no conflicts of interest regarding the publication of this paper.

\section{References}

[1] Magdi, Z. (2014) Effects of Inadequate Geotechnical Investigation on Civil Engineering Projects. International Journal of Science and Research (IJSR), 3, 927-931.

[2] Osuolale, O.M., Oseni, A.A. and Sanni, I.A. (2012) Investigation of Highway Pavement Failure Along Ibadan - Iseyin Road, Oyo State, Nigeria. International Journal of Engineering Research \& Technology (IJERT), 1, 1-6.

[3] AASHTO (2012) Classification of Soils and Soil-Aggregate Mixtures for Highway Construction Purposes. M145-91. American Association of State Highway and Transportation Officials, Washington DC.

[4] Lund, O.L. and Ramsey, W.J. (1959) Experimental Lime Stabilization in Nebraska. Highway Research Board Bull, 231, 24-57.

[5] TRAN Van Duy (2013) Étude de l'amélioration des sols par traitement à la chaux, Université de Liège.

[6] Afolayan, O.D. (2017) Evaluation of the Effect of Lime and Cement on the Engineering Properties of Selected Soil in a University in Southwestern Nigeria. Journal of Advancement in Engineering and Technology, 5, No. 4.

[7] Watson, J. (1994) Highway Construction and Maintenance. 2nd Edition. Published by Longman Group, Harlow, Essex.

[8] Tan, Y.Z., Hu, M.Z. and Li, D.Q. (2016) Effects of Agglomerate Size on California Bearing Ratio of Lime Treated Lateritic Soils. International Journal of Sustainable Built Environment, No. 5, 168-175. https://doi.org/10.1016/j.ijsbe.2016.03.002

[9] Dash, S.K. and Hussain, M. (2012) Lime Stabilization of Soils: Reappraisal. Journal of Materials in Civil Engineering, 24, 707-714. https://doi.org/10.1061/(ASCE)MT.1943-5533.0000431

[10] A1-Rawi, N.M. (1981) The Effect of Curing Temperature on Lime Stabilization. Proceedings of the 2nd Australasian Conference on Engineering Materials, Sydney, 6-8 July 1981, 611-662.

[11] Bell, F.G. (1996) Lime Stabilization of Clay Minerals and Soils. Engineering Geology, 42, 223-237. https://doi.org/10.1016/0013-7952(96)00028-2

[12] Kumar, A., Chauhan, R.S. and Kumar, A. (2016) Uniaxial Compressive Strength Enhancement in Clayey Soil with Lime Addition. International Journal of Engineering Research \& Technology, 5, 705-707. 
https://doi.org/10.17577/IJERTV5IS050979

[13] Khunt, K.P., Mishra, C.B. and Amin, A.A. (2014) Improvement in Soil Strength Using Stabilizers in Pavement. International Journal of Engineering Research \& Technology, 3, 1266-1269. https://doi.org/10.1007/978-3-642-41714-6_195231 